\title{
A Cation- $\pi$ Interaction in the Binding Site of the Glycine Receptor Is Mediated by a Phenylalanine Residue
}

\author{
Stephan A. Pless, ${ }^{1}$ Kat S. Millen, ${ }^{2}$ Ariele P. Hanek, ${ }^{4}$ Joseph W. Lynch, ${ }^{1}$ Henry A. Lester, ${ }^{5}$ Sarah C. R. Lummis, ${ }^{2,3 *}$ and \\ Dennis A. Dougherty ${ }^{4 *}$ \\ ${ }^{1}$ School of Biomedical Sciences and Queensland Brain Institute, University of Queensland, Brisbane, Queensland 4072, Australia, ${ }^{2}$ Department of \\ Biochemistry, University of Cambridge, Cambridge CB2 1QW, United Kingdom, ${ }^{3}$ Division of Neurobiology, Medical Research Council, Laboratory of \\ Molecular Biology, Cambridge CB2 2QH, United Kingdom, and Divisions of ${ }^{4} \mathrm{Chemistry}$ and Chemical Engineering and ${ }^{5}$ Biology, California Institute of \\ Technology, Pasadena, California 91125
}

Cys-loop receptor binding sites characteristically contain many aromatic amino acids. In nicotinic ACh and 5- $\mathrm{HT}_{3}$ receptors, a Trp residue forms a cation- $\pi$ interaction with the agonist, whereas in $\mathrm{GABA}_{\mathrm{A}}$ receptors, a Tyr performs this role. The glycine receptor binding site, however, contains predominantly Phe residues. Homology models suggest that two of these Phe side chains, Phe159 and Phe207, and possibly a third, Phe63, are positioned such that they could contribute to a cation- $\pi$ interaction with the primary amine of glycine. Here, we test this hypothesis by incorporation of a series of fluorinated Phe derivatives using unnatural amino acid mutagenesis. The data reveal a clear correlation between the glycine $\mathrm{EC}_{50}$ value and the cation- $\pi$ binding ability of the fluorinated Phe derivatives at position 159 , but not at positions 207 or 63 , indicating a single cation- $\pi$ interaction between glycine and Phe159. The data thus provide an anchor point for locating glycine in its binding site, and demonstrate for the first time a cation- $\pi$ interaction between Phe and a neurotransmitter.

Key words: ligand-gated ion channel; Cys-loop receptor; cation- $\pi$ interaction; unnatural amino acids; nonsense suppression; neurotransmitter

\section{Introduction}

Glycine receptors (GlyRs) mediate fast synaptic inhibition in the brainstem and spinal cord, and are involved in the generation of motor rhythm, coordination of reflex circuits, and processing of a variety of sensory signals, such as pain (Legendre, 2001; Harvey et al., 2004). GlyR are members of the Cys-loop receptor family along with $\mathrm{GABA}_{\mathrm{A}}, \mathrm{GABA}_{\mathrm{C}}, 5-\mathrm{HT}_{3}$, and nicotinic ACh receptors (nAChRs) (Le Novere and Changeux, 2001). In these receptors, five subunits are arranged pseudosymmetrically around a central ion-conducting pore; each subunit comprises a large $\mathrm{N}$-terminal ligand-binding domain, and four transmembrane helices that are connected by loops of varying size (Unwin, 1995; Miyazawa et al., 2003). Four GlyR $\alpha$ subunits and one GlyR $\beta$ subunit are known to date (for review, see Lynch, 2004).

GlyRs are emerging as pharmacological targets; thus, the exact binding mechanism of agonists and antagonists in GlyRs is of particular interest (Laube et al., 2002). Previous studies on the structure of $\mathrm{nAChRs}$ and the related acetylcholine binding pro-

Received Aug. 6, 2008; accepted Aug. 9, 2008.

This work was supported by the Wellcome Trust (S.C.R.L. is a Wellcome Trust Senior Research Fellow in Basic Biomedical Science), a Biotechnology and Biological Sciences Research Council studentship (K.S.M.), National Institutes of Health Grants NS11756 and NS34407, the Australian Research Council, a National Health and Medical Research Council of Australia Senior Research Fellowship (J.W.L.), and a University of Queensland International Postgraduate Research Scholarship (S.A.P.).

*S.C.R.L. and D.A.D. contributed equally to this work.

Correspondence should be addressed to Sarah C. R. Lummis, Department of Biochemistry, University of Cambridge, Downing Site, Cambridge CB2 10W, UK.

DOI:10.1523/JNEUROSCI.2540-08.2008

Copyright $\odot 2008$ Society for Neuroscience ～0270-6474/08/2810937-06\$15.00/0 teins (AChBPs) (Unwin, 1995; Brejc et al., 2001; Miyazawa et al., 2003) have confirmed the location of the agonist binding site at the subunit interface. The binding site is formed by three loops from one subunit $(\mathrm{A}-\mathrm{C})$ and three $\beta$ strands from the adjacent subunit $(\mathrm{D}-\mathrm{F})$. The binding pockets are rich in aromatic residues, and previous studies have shown that a cation- $\pi$ interaction between an aromatic binding site residue and the positively charged amine on the natural agonist makes a substantial contribution to agonist binding in $\mathrm{nACh}, 5-\mathrm{HT}_{3}$, modulation of locomotion defective 1 (MOD-1), $\mathrm{GABA}_{\mathrm{A}}$, and $\mathrm{GABA}_{\mathrm{C}}$ receptors. Interestingly, the nature and location of the aromatic residue that interacts with the cation is not conserved; thus, the residue is Trp on loop B in nACh and $5-\mathrm{HT}_{3}$ receptors, Tyr on loop $\mathrm{B}$ in $\mathrm{GABA}_{\mathrm{C}}$ receptors, Tyr on loop A in $\mathrm{GABA}_{\mathrm{A}}$ receptors, and Trp on loop C in MOD-1 receptors (Zhong et al., 1998; Beene et al., 2002; Mu et al., 2003; Lummis et al., 2005; Padgett et al., 2007).

In the GlyR binding site, Phe residues are located at all of the positions homologous to those involved in cation- $\pi$ interactions in other Cys-loop receptors (see Table 1). A recent study has implicated Phe159 and Phe207 in a joint cation- $\pi$ interaction with the glycine amino group based on the results of conventional mutagenesis and a computational model (Grudzinska et al., 2005). To date, no cation- $\pi$ interaction identified in a Cys-loop receptor has involved two contributing amino acid residues. To determine whether such an interaction exists requires direct experimental evidence either in the form of high-resolution structural data (not yet available for GlyRs) or by the incorporation of unnatural amino acids (Dougherty, 2000; Beene et al., 2003). 
<smiles>CCc1ccccc1</smiles><smiles>CCc1ccc(C)cc1</smiles><smiles>CCc1ccc(OC)cc1</smiles><smiles>CCc1ccc(C#N)cc1</smiles>

Phe<smiles>CCc1ccc(F)cc1</smiles>

4-Me-Phe<smiles>CCc1cc(F)cc(F)c1</smiles>

3,5- $\mathrm{F}_{2}-\mathrm{Phe}$<smiles>CCc1cc(F)c(F)c(F)c1</smiles>

$3,4,5-\mathrm{F}_{2}-\mathrm{Phe}$

Figure 1. Structures of both the natural and unnatural side chains incorporated by the nonsense suppression method. Carbon numbering as highlighted in the phenylalanine structure.

Here, we applied nonsense suppression methodology to incorporate unnatural amino acids, in combination with radioligand binding studies and computational modeling, to determine whether one or more Phe residues contributes to a cation- $\pi$ interaction in the GlyR binding site.

\section{Materials and Methods}

Mutagenesis and preparation of mRNA and oocytes. The human GlyR $\alpha_{1}$ subunit cDNA was subcloned into pGEMHE (for oocyte expression) or pcDNA3.1 (for binding studies). Site-directed mutagenesis was performed with the QuickChange mutagenesis kit (Stratagene). The mMessage mMachine kit (Ambion) was used to generate capped mRNA for oocyte injection. Xenopus laevis (Nasco) oocytes were prepared as described previously (Pless et al., 2007), and injected with $10 \mathrm{ng}$ of mRNA. After injection, oocytes were incubated for $24 \mathrm{~h}$ at $18^{\circ} \mathrm{C}$.

Synthesis of tRNA and dCA amino acids. This was performed as described previously (Beene et al., 2004). In brief, unnatural amino acids (Fig. 1) were chemically synthesized as NVOC (nitroveratryloxycarbonyl)-protected cyanomethyl esters. They were coupled to the dinucleotide $\mathrm{dCA}$, which was then enzymatically ligated to a 74-mer

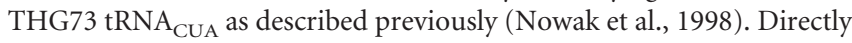
before coinjection with the mRNA, the aminoacyl tRNA was deprotected by photolysis (Kearney et al., 1996). In a typical experiment, $10 \mathrm{ng}$ of mRNA was injected with $25 \mathrm{ng}$ of tRNA-aa in a total volume of $50 \mathrm{nl}$. In control experiments, mRNA was injected alone or together with THG74dCA tRNA (with no unnatural amino acid attached).

Characterization of mutant receptors. Peak glycine-induced currents were recorded from individual oocytes using the OpusXpress voltageclamp system (Molecular Devices). All recordings were performed at $22-25^{\circ} \mathrm{C}$. Glycine (Sigma) was stored as $1 \mathrm{M}$ aliquots at $-20^{\circ} \mathrm{C}$, diluted in ND96 [(in mM) $96 \mathrm{NaCl}, 2 \mathrm{KCl}, 1 \mathrm{MgCl}_{2}, 1.8 \mathrm{CaCl}_{2}, 5$ HEPES, pH 7.4] before experiments, and delivered to the cells using the computercontrolled perfusion system of OpusXpress. Glass microelectrodes were backfilled with $3 \mathrm{M} \mathrm{KCl}$ and had resistances between 0.5 and $3 \mathrm{M} \Omega$. All recordings were performed at a holding potential of $-60 \mathrm{mV}$. The empirical Hill equation, fitted with a nonlinear least squares algorithm, was used to obtain half-maximal concentrations $\left(\mathrm{EC}_{50}\right)$ and Hill coefficient $\left(n_{\mathrm{H}}\right)$ values for ligand-induced activation (SigmaPlot 9.0, Systat Software). Data represent mean \pm SEM.

Radioligand binding. This was undertaken as described previously with minor modifications (Price and Lummis, 2004). Briefly, transfected human embryonic kidney 293 cell membranes were incubated for $1 \mathrm{~h}$ at

Table 1. Residues contributing to the aromatic box in the Cys-loop receptor family

\begin{tabular}{llllll}
\hline Receptor & A & B & C & & D \\
\hline nACh & Y93 & W149 & Y190 & Y198 & W55 \\
5-HT & E129 & W183 & F226 & Y234 & W90 \\
MOD-1 $_{\text {GABA }}$ & C120 & Y180 & Y221 & W226 & F83 \\
GABA $_{\text {A }}$ & F138 & Y198 & Y241 & Y247 & Y102 \\
Gly & Y97 & Y157 & F200 & Y205 & F65 \\
\hline
\end{tabular}

Appropriate binding segments are labeled accordingly. Residues in bold have been shown to be involved in cation- $\pi$ interactions.

$20^{\circ} \mathrm{C}$ in $0.5 \mathrm{ml}$ of phosphate buffer $(50 \mathrm{~mm}, \mathrm{pH} 7.4)$ containing the glycine receptor antagonist $\left[{ }^{3} \mathrm{H}\right]$ strychnine at $0.1-40 \mathrm{~nm}$. Nonspecific binding was determined using $1 \mathrm{~mm}$ glycine. Data were analyzed by iterative curve fitting (Prism version 3.0; GraphPad Software) according to the equation $B=\left(B_{\max }[L]\right) /\left(K_{\mathrm{d}}+[L]\right)$, where $B$ is bound radioligand, $B_{\max }$ is maximum binding at equilibrium, $K_{\mathrm{d}}$ is the equilibrium dissociation constant, and $[L]$ is the free concentration of radioligand. Data represent mean \pm SEM. Statistical analysis was performed using ANOVA in conjunction with a Dunnett's post test.

Modeling. This was performed as described previously (Reeves et al., 2003; Thompson et al., 2005). Three-dimensional models of the extracellular region of the glycine receptor were built using MODELLER 6, version 2 (Sali and Blundell, 1993), based on the crystal structure of AChBP in the agonist-bound state (carbamylcholine, PDB ID; 1uv6). The model was energy minimized in SYBYL version 6.8 using the AMBER force field by moving side chains alone (Weiner et al., 1984). Models were viewed using ViewerLite version 5.0. Docking was performed using GOLD 3.0 (The Cambridge Crystallographic Data Centre, Cambridge, UK) as described previously (Thompson and Lummis, 2007).

\section{Results}

\section{Locating potential cation- $\pi$ interacting residues}

An alignment of amino acid residues contributing to the aromatic box in Cys-loop receptors reveals that Phe63, Phe99, Phe159, Tyr202, and Phe207 of the GlyR are all possible candidates to contribute to a cation- $\pi$ interaction (Table 1 ). Because Phe99 and Tyr202 could be ruled out on the basis of previous studies using conventional mutagenesis (see Discussion), only Phe63, Phe159, and Phe 207 were selected for unnatural amino acid incorporation. These amino acids were substituted with Phe analogues with an increasing number of fluorine substituents. A hydrogen to fluorine substitution in the benzene ring of aromatic residues is deactivating in the cation- $\pi$ interaction, and the effects of multiple fluorine substitutions are additive (Zhong et al., 1998). Thus, a systematic decrease in agonist affinity with increasing fluorination provides compelling evidence for a cation- $\pi$ interaction. The reluctance to participate in $\mathrm{H}$-bonding interactions and small steric size further make fluorine an ideal substituent.

\section{Validation of the nonsense suppression method}

Fluorinated Phe residues were incorporated using nonsense suppression. To validate this method, we coinjected the mutant $\mathrm{mR}-$ NAs and a suppressor tRNA chemically aminoacylated with Phe. When coinjected with Phe-tRNA, mutant mRNAs encoding Phe63TAG, Phe159TAG, Phe207TAG, and Phe159TAG/ Phe207TAG receptors produced functional receptors that responded to the application of glycine. Maximal currents $\left(I_{\max }\right)$ and $\mathrm{EC}_{50}$ and $n_{\mathrm{H}}$ values were similar to each other, and to previously published results for wild-type (WT) $\alpha_{1}$ homopentameric GlyRs expressed in Xenopus oocytes (De Saint Jan et al., 2001). We thus conclude that the wild-type phenotype is successfully "rescued" by the nonsense suppression method.

No currents were recorded in response to high ( $5 \mathrm{~mm})$ con- 
Table 2. Dose-response data for GlyR with unnatural amino acids at positions 63, 159,207 , and the 159/207 double-mutant construct

\begin{tabular}{|c|c|c|c|c|}
\hline Mutant & $\mathrm{EC}_{50}(\mu \mathrm{M})$ & $n_{\mathrm{H}}$ & $I_{\max }(\mathrm{mA})$ & $n$ \\
\hline 63-Phe (WT) & $113 \pm 4$ & $2.6 \pm 0.2$ & $8.6 \pm 1.4$ & 7 \\
\hline $63-F_{1}-$ Phe & $34.5 \pm 0.1^{*}$ & $2.8 \pm 0.1$ & $8.9 \pm 0.7$ & 7 \\
\hline $63-F_{2}-$ Phe & $210 \pm 9^{*}$ & $2.1 \pm 0.2$ & $3.2 \pm 1.1^{*}$ & 3 \\
\hline 63-CN-Phe & $6.5 \pm 0.4^{*}$ & $2.7 \pm 0.4$ & $7.9 \pm 1.5$ & 5 \\
\hline $63-F_{3}-$ Phe & $348 \pm 19^{*}$ & $1.8 \pm 0.2$ & $4.2 \pm 0.7^{*}$ & 5 \\
\hline 159-Phe (WT) & $109 \pm 2$ & $2.8 \pm 0.2$ & $7.4 \pm 0.6$ & 5 \\
\hline 159-F - Phe & $288 \pm 6^{*}$ & $3.1 \pm 0.2$ & $6.8 \pm 1.1$ & 4 \\
\hline $159-F_{2}-$ Phe & $11000 \pm 200^{*}$ & $2.0 \pm 0.1^{*}$ & $7.7 \pm 0.6$ & 6 \\
\hline 159-CN-Phe & $46100 \pm 1400^{*}$ & $1.9 \pm 0.1^{*}$ & $9.2 \pm 1.2$ & 9 \\
\hline $159-\mathrm{F}_{3}$-Phe & $103000 \pm 2700^{*}$ & $2.3 \pm 0.1$ & $5.6 \pm 0.6$ & 7 \\
\hline 207-Phe (WT) & $114 \pm 3$ & $2.2 \pm 0.1$ & $10.8 \pm 1.1$ & 4 \\
\hline 207-ME-Phe & $1020 \pm 20^{*}$ & $2.2 \pm 0.1$ & $10.1 \pm 3.3$ & 4 \\
\hline 207-0-ME-Phe & $2520 \pm 140^{*}$ & $2.2 \pm 0.3$ & $10.3 \pm 0.4$ & 4 \\
\hline 207-F 1 -Phe & $151 \pm 4$ & $2.4 \pm 0.1$ & $9.5 \pm 2.6$ & 4 \\
\hline $207-F_{2}-$ Phe & $56700 \pm 600^{*}$ & $2.4 \pm 0.1$ & $8.1 \pm 0.2^{*}$ & 5 \\
\hline 207-CN-Phe & $3910 \pm 60^{*}$ & $2.6 \pm 0.1$ & $9.7 \pm 1.4$ & 4 \\
\hline 207-F_-Phe & $13500 \pm 700^{*}$ & $2.4 \pm 0.2$ & $8.4 \pm 1.2$ & 8 \\
\hline 159,207-Phe (WT) & $131 \pm 1$ & $2.7 \pm 0.1$ & $9.3 \pm 1.3$ & 18 \\
\hline $159,207-F_{1}-$ Phe & $287 \pm 10^{*}$ & $2.6 \pm 0.3$ & $7.7 \pm 1.7$ & 13 \\
\hline
\end{tabular}

Data are mean \pm SEM

${ }^{*} p<0.05$, significantly different from WT rescue (Student's $t$ test).

centrations of glycine from oocytes injected with mutant mRNA alone or with mutant mRNA and tRNA-dCA with no amino acid attached ( $n=6$ each). This indicates that the stop codon at the position of the mutated phenylalanine, as expected, generates truncated and consequently nonfunctional receptors. Additionally, this control shows that no endogenous tRNA-aa of the oocyte incorporates a functional amino acid at the mutated sites. Finally, endogenous synthetases do not seem to reacylate the tRNAs with naturally occurring amino acids, because we did not detect currents when mRNA and nonligated tRNA were coinjected $(n=6)$.

\section{GlyR Phe63}

Introduction of a single fluorine in the 4 position decreased the $\mathrm{EC}_{50}$ value by a factor of three (Table 2). Introducing a cyano (CN) group at the same position caused a larger (17-fold) drop in $\mathrm{EC}_{50}$. Cyano is strongly deactivating in a cation- $\pi$ interaction (Zhong et al., 1998), and its introduction at a site that contributes to such an interaction would have the opposite effect, i.e., cause a substantial increase in $\mathrm{EC}_{50}$. Thus, we can rule out a cation- $\pi$ interaction at Phe63. Consistent with this reasoning, substitution with $3,5-\mathrm{F}_{2}-\mathrm{Phe}$ or $3,4,5-\mathrm{F}_{3}-$ Phe caused relatively small (twofold to threefold) changes in $\mathrm{EC}_{50}$ value that produce no consistent trend when combined with $\mathrm{F}_{1}-\mathrm{Phe}$ data. We note that $3,5-\mathrm{F}_{2}-\mathrm{Phe}$ and 3,4,5- $\mathrm{F}_{3}-\mathrm{Phe}$ produced significantly lower maximal currents (3.2 \pm 1.1 and $4.2 \pm 0.7 \mu \mathrm{A}$, respectively), which may explain the higher $\mathrm{EC}_{50}$ values (De Saint Jan et al., 2001). Previously, Grudzinska et al. (2005) proposed a cation- $\pi$ interaction between Phe63 and the guanidinium group of Arg65. The present results do not support this proposal.

Radioligand binding data reveal Ala substitution results in nonbinding receptors, whereas Tyr substitution yields receptors with a $K_{\mathrm{d}}$ similar to wild type $(11.2 \pm 4.4 \mathrm{~nm}$ vs $5.6 \pm 1.7 \mathrm{~nm}$ in WT).

\section{GlyR Phe159}

Successive addition of fluorines to Phe159 leads to a progressive decrease in glycine sensitivity (Fig. $2 A, B$, Table 2), indicating a cation- $\pi$ interaction at this site, and $4-\mathrm{CN}$-Phe generates an $\mathrm{EC}_{50}$ value intermediate between those for $3,5-\mathrm{F}_{2}-\mathrm{Phe}$ and $3,4,5-\mathrm{F}_{3}-$ Phe, as could be predicted by their cation- $\pi$ binding ability [determined as described by Mecozzi et al. (1996)]. As in previous studies with Trp and Tyr, the "fluorination plot" (Zhong et al., 1998) shown in Figure $2 C$ demonstrates a strong linear correlation between the cation- $\pi$ binding ability and relative $\log \mathrm{EC}_{50}$ value (scaled to wild type). The magnitude and consistency of the effect show a significant cation- $\pi$ interaction at Phe159.

$\left[{ }^{3} \mathrm{H}\right]$ strychnine binding supported the hypothesis as the Phe159Tyr mutant produced values that are not significantly different from wild-type receptors $\left(K_{\mathrm{d}}=3.8 \pm 1.1 \mathrm{~nm}\right.$ vs $5.6 \pm 1.7$ $\mathrm{nM}$ in WT), whereas Phe159Ala receptors had no specific binding.

\section{GlyR Phe207}

The addition of a single fluorine at Phe207 $\left(\mathrm{F}_{1}-\mathrm{Phe}\right)$ resulted in no change in the glycine $\mathrm{EC}_{50}$ value (Table 2). However, the addition of larger groups (4-Me-Phe, 4-OMe-Phe, and 4-CN$\mathrm{Phe}$ ) yielded $\mathrm{EC}_{50}$ values 10 - to 30 -fold higher. 3,5- $\mathrm{F}_{2} \mathrm{Phe}$ and $3,4,5-\mathrm{F}_{3}$ Phe yielded large increases in $\mathrm{EC}_{50}$ (500-fold and 100fold, respectively). Together, these results are not consistent with a cation- $\pi$ interaction involving Phe207, because there is no apparent correlation with the cation- $\pi$ binding ability of the incorporated unnatural amino acid, and any substituent added to the benzene ring increases the $\mathrm{EC}_{50}$.

Additional evidence against a cation- $\pi$ interaction at Phe 207 stems from results with the Phe159TAG/Phe207TAG doublemutant receptor. If Phe159 and Phe207 both contribute to a cation- $\pi$ interaction with the glycine amine group, a large increase in $\mathrm{EC}_{50}$ would be expected when both interactions are simultaneously weakened. This was, however, not the case. Receptors containing the Phe159TAG/Phe207TAG mutation displayed robust expression and electrophysiological properties similar to those of wild-type receptors when coinjected with PhetRNA (Fig. 3). Addition of a single fluorine (4- $\mathrm{F}_{1}-\mathrm{Phe)}$ to both sites produced receptors with only a small decrease in glycine sensitivity (Table 2). The Phe159TAG/Phe207TAG double mutant did not produce a functional receptor with 3,5- $\mathrm{F}_{2}$ Phe-tRNA. However, introduction of a cyano group (4-CN-Phe) yielded receptors displaying a greatly reduced glycine sensitivity, with an $\mathrm{EC}_{50}$ value in excess of $400 \mathrm{~mm}$ (Fig. 3).

Phe207Ala abolished $\left[{ }^{3} \mathrm{H}\right]$ strychnine binding, and Phe207Tyr yielded values for binding significantly higher than that of WT receptors $\left(K_{\mathrm{d}}=71.9 \pm 4.5 \mathrm{nM}\right)$. Given that the same mutation had no measurable effect on the glycine $\mathrm{EC}_{50}$ value (data not shown), this suggests that the shape of the binding site around Phe207 is more critical for strychnine than for glycine binding. Additionally, because of the very similar cation- $\pi$ binding abilities of Phe and Tyr, our data argue against a cation- $\pi$ interaction between the protonated N19 of strychnine, as suggested by Grudzinska et al. (2005).

\section{Discussion}

Here, we show that there is a cation- $\pi$ interaction with Phe159 on loop B in the GlyR. This is the sixth Cys-loop receptor for which a linear fluorination plot has revealed a single cation- $\pi$ interaction. These data show the most common location for a cation- $\pi$ interaction is an aromatic on loop B (Trp 149 of the nAChR, Trp 183 of the $5-\mathrm{HT}_{3} \mathrm{R}$, Tyr 198 of the $\mathrm{GABA}_{\mathrm{C}}$ receptor, and Phe159 of the GlyR). However, cation- $\pi$ interactions with residues on loop A (Tyr97 in the $\mathrm{GABA}_{\mathrm{A}}$ receptor) and loop $\mathrm{C}$ ( Trp226 on the MOD-1 receptor) have also been observed, indicating neither the location nor the identity of the aromatic residue that participates 
in this interaction is conserved throughout this receptor family. The fluorination plots of all of these receptors (Fig. 2D) show that there is some variation in the slopes of the plots. ACh has the shallowest slope, which may be because the quaternary ammonium $\left[\mathrm{RN}\left(\mathrm{CH}_{3}\right)_{3}{ }^{+}\right]$of ACh presents a less focused positive charge than the primary ammonium $\left(\mathrm{RNH}_{3}{ }^{+}\right)$of $5-\mathrm{HT}_{3}, \mathrm{GABA}$, and glycine; the strong electrostatic component of the cation- $\pi$ interaction means that a more focused charge should produce a stronger effect.

Previous studies in the GlyR, based mostly on modeling data, suggested that a cation- $\pi$ interaction involving both Phe159 and Tyr207 may exist, although no direct evidence was shown (Grudzinska et al., 2005); these residues, and also Phe63, were all possible candidates for such an interaction. There are other aromatic residues in the binding pocket (Tyr161, Phe99, Phe100, and Tyr202), but previous data suggest that these are unlikely to contribute to a cation- $\pi$ interaction. For Tyr161, the nonaromatic Tyr161Ala mutation results in only a moderate $(\sim 10$ fold) loss in glycine sensitivity (Vandenberg et al., 1992b; Yang et al., 2007), and similarly, Ala substitutions of Phe99 and Phe100 in loop B result in only small changes of the $\mathrm{EC}_{50}$ value (Vafa et al., 1999). For Tyr202, it has been convincingly demonstrated that the hydroxyl group of Tyr202 and not its aromatic character is crucial for agonist binding (Rajendra et al., 1995).

The cationic moiety contributing to the cation- $\pi$ interaction at Phe159 could, in theory, originate from a positively charged amino acid such as Arg65, Arg 131, Lys200, or Lys206, which are all in close proximity. Arg65 is proposed to make contact with the carboxylate of glycine, locating this residue at the opposite end of the binding pocket (Grudzinska et al., 2005), whereas neutralizing Arg131 (in Arg131Ala mutant receptors), Lys200 (Lys200Ala) or Lys206 (Lys206Ala) shows only a moderate or no effect on the glycine $\mathrm{EC}_{50}$ value (Vandenberg et al., 1992a; Yang et al., 2007). We thus conclude that Phe159 forms a direct cation- $\pi$ interaction with the positive amine of glycine.

Our model of glycine docked into the binding site (Fig. 4) is consistent with the experimental data in showing the potential for a cation- $\pi$ interaction between glycine and Phe159, and is also consistent with an interaction of the carboxylate of glycine and Arg65 as discussed above. As in the previous model used by Grudzinska et al. (2005), however, the location of the positive amine in our model is not inconsistent with a cation- $\pi$ interaction at Phe207. This finding therefore emphasizes the importance of experimental data to support and are omitted for clarity.
A

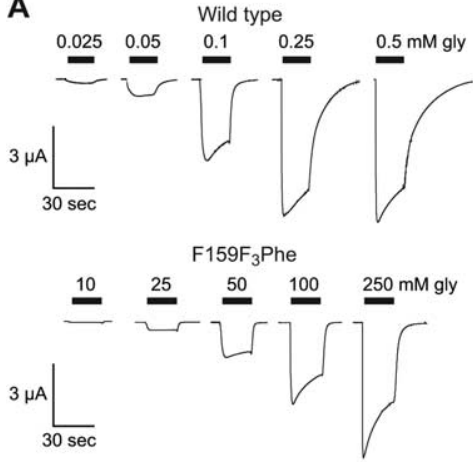

C

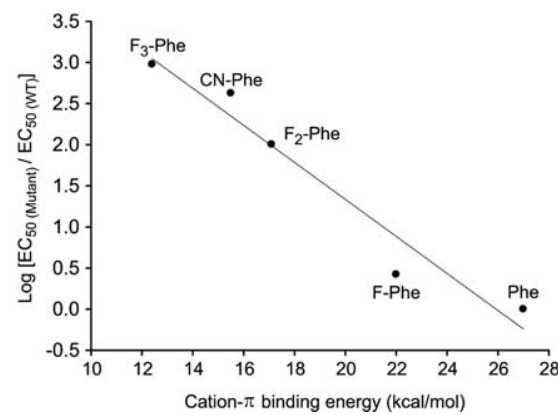

B

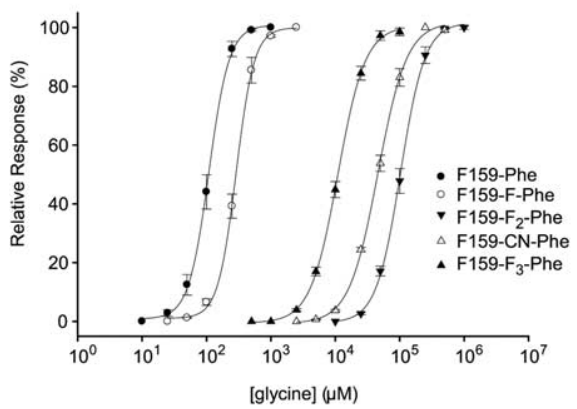

D

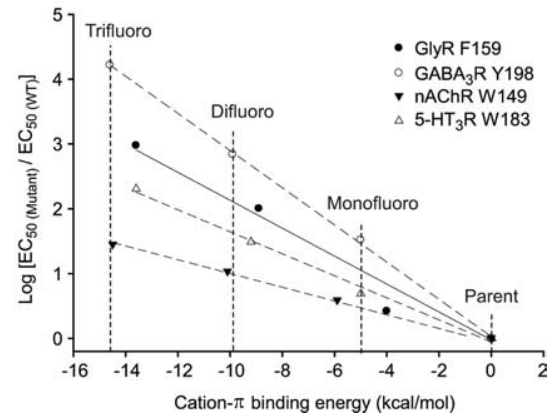

Figure 2. GlyR responses from Phe159 mutant receptors yield a linear fluorination plot. $A$, Current traces recorded from oocytes coinjected with GlyR F159TAG mRNA and Phe tRNA (i.e., WT receptors; top) or GlyR Phe159TAG mRNA and F F $_{3}$ Phe tRNA (bottom). Horizontal bars indicate the duration of glycine application. $\boldsymbol{B}$, Glycine-induced current dose-response curves. $\boldsymbol{C}$, Fluorination plot of the GlyR Phe 159 mutants; $\log \mathrm{EC}_{50}$ value (based on data in Table 2) normalized to the wild-type $\log \mathrm{EC}_{50}$ value. Linear fit resulted in $y=5.84-0.22$ ( $r=0.99)$. $\boldsymbol{D}$, Fluorination plots comparing the cation- $\pi$ interactions of Gly, $\mathrm{nACh}, \mathrm{GABA}_{\mathrm{A}}, \mathrm{and}_{5}-\mathrm{HT}_{3}$ receptors. The $x$-axis is offset so the nonfluorinated parent side chain equals 0 (Trp for $n A C h R$, and $5-H_{3}$ and $P$ he for $G A B A_{A} R$ and GlyR, respectively). Note that the value for CN-Phe is omitted in the gradient for the GlyR (the linear fit is virtually unchanged: $y=$ $5.58-0.22 ; r=0.99)$. The gradients for MOD- 1 and GABA $R$ are almost identical to those of the $5-H_{3} R$ and the GlyR, respectively,
A

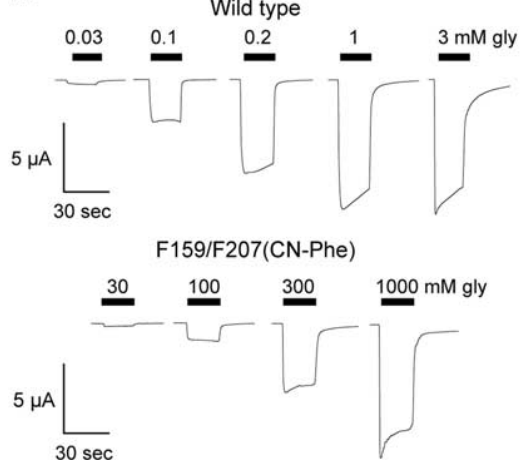

B

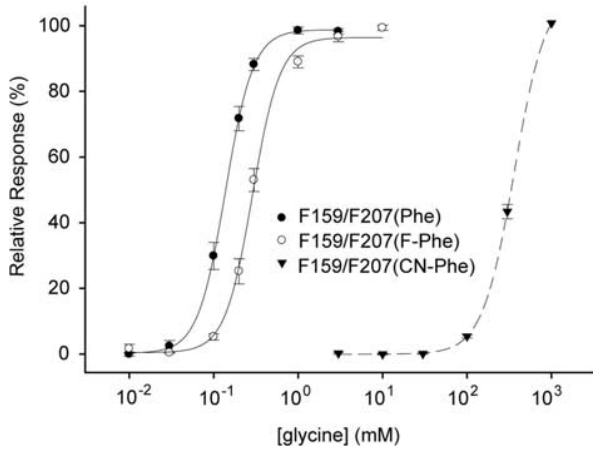

Figure 3. Phe159TAG/Phe207TAG double-mutant receptor responses. $\boldsymbol{A}$, Current recordings from Phe159TAG/Phe207TAG mRNA coinjected with Phe tRNA (top) or CN-Phe tRNA (bottom). Horizontal bars indicate the duration of glycine application. $\boldsymbol{B}$, Glycine-induced current dose-response relationships and fits to the Hill equation for GlyR Phe159TAG/Phe207TAG mRNA injected with different tRNAs. Note that the dashed line for $\mathrm{CN}$-Phe indicates that the $\mathrm{EC}_{50}$ value cannot be determined accurately because of the high glycine concentrations required.

modeling and docking studies. Our data with Phe207 do not support a cation- $\pi$ interaction with this residue. We also performed experiments with double-mutant receptors (Phe159/ Phe207) to confirm this finding. The measured $\mathrm{EC}_{50}$ value of $\sim 300 \mu \mathrm{M}$ for receptors with F-Phe at both of these positions is close to the calculated value of $\sim 380 \mu \mathrm{M}$ that would be expected if the $\mathrm{EC}_{50}$ value were simply the product of the two individual mutations. Substitution with $4-\mathrm{CN}-\mathrm{Phe}$, although not 3,5- $\mathrm{F}_{2}-$ 


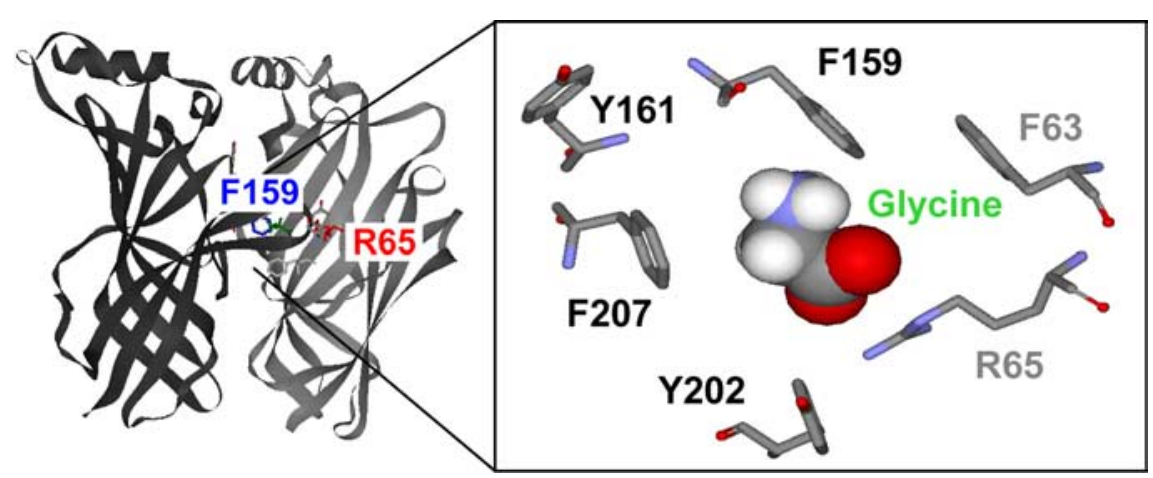

Figure 4. Homology model of the extracellular domain of the GlyR based on the crystal structure of AChBP with carbamylcholine bound (PDB ID; 1uv6). For ease of viewing, only two of the five subunits have been shown. The ligand binding site is located between the two subunits; glycine (green), F159 (blue), and R65 (red) are colored for clarity. Inset, Enlargement of residues examined in this study showing that docking of glycine is consistent with a cation- $\pi$ interaction with Phe159, and also with previous studies on Arg 65, which is proposed to make contact with the carboxylate of glycine (Grudzinska et al., 2005). The two images are in different orientations for clarity.

Phe, at both sites resulted in functional receptors, although the glycine $\mathrm{EC}_{50}$ value (>400 mM) could not be determined (Fig. 3). However, these data are consistent with the calculated $\mathrm{EC}_{50}$ value of $\sim 1.5 \mathrm{M}$ glycine for a multiplicative effect of the $\mathrm{EC}_{50}$ values for the single mutations Phe159CN-Phe and Phe207CN-Phe. Together, the results from both the Phe207TAG single mutant and the Phe159TAG/Phe207TAG double mutant support the presence of only one cation- $\pi$ interaction in the GlyR binding site, namely that at position 159 .

The current data rule out a cation- $\pi$ interaction at position 207 , although the presence of an aromatic seems to be imperative for proper receptor function, as demonstrated by the present study and previous work (Grudzinska et al., 2005). Because glycine is a smaller molecule than the ligands that activate other Cys-loop neurotransmitters, the GlyR binding site may be more compact than any of the other aromatic boxes examined thus far, which could make it more sensitive to incorporation of Phe analogues that have a steric effect. This proposal is supported by the fact that the glycine $\mathrm{EC}_{50}$ value is affected by the bulk of the group attached to the 4 position of Phe207. The results also suggest that groups added to the Phe207 benzene ring exert an even stronger effect when added to the 3 and/or 5 position.

Thus, in conclusion, our data show a strong correlation between receptor function and the cation- $\pi$ binding abilities of Phe analogues when they are incorporated at position 159, indicating a cation- $\pi$ interaction between the primary amine of glycine and the side chain of Phe at this location. Our experimental data rule out cation- $\pi$ interactions at Phe63 and Phe207. Similar to the agonist glycine, the competitive antagonist strychnine requires the presence of aromatic side chains at positions 63, 159, and 207. Importantly, strychnine appears more sensitive to alterations at position 207 than glycine, providing insight into the molecular differences in the recognition of agonists and antagonists by neurotransmitter receptors. An accurate knowledge of the correct orientation of the neurotransmitter and the nature of the interactions involved in the binding event is important for understanding its mechanism of action. Because there is now an increasing number of models of the binding sites of Cys-loop receptors available, this information will help to delineate receptor-specific differences (as well as similarities) within this neurotransmitter receptor family and thus provide the basis for rational drug design in the future.

\section{References}

Beene DL, Brandt GS, Zhong W, Zacharias NM, Lester HA, Dougherty DA (2002) Cation- $\pi$ interactions in ligand recognition by serotonergic $\left(5-\mathrm{HT}_{3 \mathrm{~A}}\right)$ and nicotinic acetylcholine receptors: the anomalous binding properties of nicotine. Biochemistry 41:10262-10269.

Beene DL, Dougherty DA, Lester HA (2003) Unnatural amino acid mutagenesis in mapping ion channel function. Curr Opin Neurobiol 13:264-270.

Beene DL, Price KL, Lester HA, Dougherty DA, Lummis SC (2004) Tyrosine residues that control binding and gating in the 5-hydroxytryptamine 3 receptor revealed by unnatural amino acid mutagenesis. J Neurosci 24:9097-9104.

Brejc K, van Dijk WJ, Klaassen RV, Schuurmans M, van Der Oost J, Smit AB, Sixma TK (2001) Crystal structure of an ACh-binding protein reveals the ligand-binding domain of nicotinic receptors. Nature 411:269-276.

De Saint Jan D, David-Watine B, Korn H, Bregestovski $\mathrm{P}$ (2001) Activation of human $\alpha 1$ and $\alpha 2$ homomeric glycine receptors by taurine and GABA. J Physiol 535:741-755.

Dougherty DA (2000) Unnatural amino acids as probes of protein structure and function. Curr Opin Chem Biol 4:645-652.

Grudzinska J, Schemm R, Haeger S, Nicke A, Schmalzing G, Betz H, Laube B (2005) The beta subunit determines the ligand binding properties of synaptic glycine receptors. Neuron 45:727-739.

Harvey RJ, Depner UB, Wässle H, Ahmadi S, Heindl C, Reinold H, Smart TG, Harvey K, Schütz B, Abo-Salem OM, Zimmer A, Poisbeau P, Welzl H, Wolfer DP, Betz H, Zeilhofer HU, Müller U (2004) GlyR $\alpha 3$ : an essential target for spinal PGE2-mediated inflammatory pain sensitization. Science 304:884-887.

Kearney PC, Nowak MW, Zhong W, Silverman SK, Lester HA, Dougherty DA (1996) Dose-response relations for unnatural amino acids at the agonist binding site of the nicotinic acetylcholine receptor: tests with novel side chains and with several agonists. Mol Pharmacol 50:1401-1412.

Laube B, Maksay G, Schemm R, Betz H (2002) Modulation of glycine receptor function: a novel approach for therapeutic intervention at inhibitory synapses? Trends Pharmacol Sci 23:519-527.

Legendre P (2001) The glycinergic inhibitory synapse. Cell Mol Life Sci 58:760-793.

Le Novere N, Changeux JP (2001) The ligand gated ion channel database: an example of a sequence database in neuroscience. Phil Trans R Soc Lond B Biol Sci 356:1121-1130.

Lummis SC, L Beene D, Harrison NJ, Lester HA, Dougherty DA (2005) A cation- $\pi$ binding interaction with a tyrosine in the binding site of the $\mathrm{GABA}_{\mathrm{C}}$ receptor. Chem Biol 12:993-997.

Lynch JW (2004) Molecular structure and function of the glycine receptor chloride channel. Physiol Rev 84:1051-1095.

Mecozzi S, West AP Jr, Dougherty DA (1996) Cation- $\pi$ interactions in aromatics of biological and medicinal interest: electrostatic potential surfaces as a useful qualitative guide. Proc Natl Acad Sci USA 93:10566-10571.

Miyazawa A, Fujiyoshi Y, Unwin N (2003) Structure and gating mechanism of the acetylcholine receptor pore. Nature 423:949-955.

Mu TW, Lester HA, Dougherty DA (2003) Different binding orientations for the same agonist at homologous receptors: a lock and key or a simple wedge? J Am Chem Soc 125:6850-6851.

Nowak MW, Gallivan JP, Silverman SK, Labarca CG, Dougherty DA, Lester HA (1998) In vivo incorporation of unnatural amino acids into ion channels in Xenopus oocyte expression system. Methods Enzymol 293:504-529.

Padgett CL, Hanek AP, Lester HA, Dougherty DA, Lummis SC (2007) Unnatural amino acid mutagenesis of the $\mathrm{GABA}_{\mathrm{A}}$ receptor binding site residues reveals a novel cation- $\pi$ interaction between GABA and $\beta_{2}$ Tyr97. J Neurosci 27:886-892.

Pless SA, Dibas MI, Lester HA, Lynch JW (2007) Conformational variability 
of the glycine receptor M2 domain in response to activation by different agonists. J Biol Chem 282:36057-36067.

Price KL, Lummis SC (2004) The role of tyrosine residues in the extracellular domain of the 5-hydroxytryptamine ${ }_{3}$ receptor. J Biol Chem 279:23294-23301.

Rajendra S, Vandenberg RJ, Pierce KD, Cunningham AM, French PW, Barry PH, Schofield PR (1995) The unique extracellular disulfide loop of the glycine receptor is a principal ligand binding element. EMBO J 14:2987-2998.

Reeves DC, Sayed MF, Chau PL, Price KL, Lummis SC (2003) Prediction of $5-\mathrm{HT}_{3}$ receptor agonist-binding residues using homology modeling. Biophys J 84:2338-2344.

Sali A, Blundell TL (1993) Comparative protein modelling by satisfaction of spatial restraints. J Mol Biol 234:779-815.

Thompson AJ, Lummis SC (2007) The antimalarial drugs quinine, chloroquine and mefloquine are antagonists at $5-\mathrm{HT}_{3}$ receptors. Br J Pharmacol 151:666-667.

Thompson AJ, Price KL, Reeves DC, Chan SL, Chau PL, Lummis SCR (2005) Locating an antagonist in the $5-\mathrm{HT}_{3}$ receptor binding site using modeling and radioligand binding. J Biol Chem 280:20476-20482.
Unwin N (1995) Acetylcholine receptor channel imaged in the open state Nature 373:37-43.

Vafa B, Lewis TM, Cunningham AM, Jacques P, Lynch JW, Schofield PR (1999) Identification of a new ligand binding domain in the $\alpha 1$ subunit of the inhibitory glycine receptor. J Neurochem 73:2158-2166.

Vandenberg RJ, Handford CA, Schofield PR (1992a) Distinct agonist- and antagonist-binding sites on the glycine receptor. Neuron 9:491-496.

Vandenberg RJ, French CR, Barry PH, Shine J, Schofield PR (1992b) Antagonism of ligand-gated ion channel receptors: two domains of the glycine receptor $\alpha$ subunit form the strychnine-binding site. Proc Natl Acad Sci U S A 89:1765-1769.

Weiner SJ, Kollman PA, Case DA, Singh UC, Ghio C, Alagona G, Profeta S, Weiner P (1984) A new force-field for molecular mechanical simulation of nucleic-acids and proteins. J Am Chem Soc 106:765-784

Yang Z, Ney A, Cromer BA, Ng HL, Parker MW, Lynch JW (2007) Tropisetron modulation of the glycine receptor: femtomolar potentiation and a molecular determinant of inhibition. J Neurochem 100:758-769.

Zhong W, Gallivan JP, Zhang Y, Li L, Lester HA, Dougherty DA (1998) From ab initio quantum mechanics to molecular neurobiology: a cation- $\pi$ binding site in the nicotinic receptor. Proc Natl Acad Sci U S A 95:12088-12093. 